\title{
Synthesis and Characterisation of Hydroxyl-terminated Liquid Natural Rubber by Photo-Fenton Reaction
}

\author{
H. L. PHAM ${ }^{1 *}$, B. T. DO ${ }^{1}$, T. S. PHAM ${ }^{1}$ AND D. G. LE ${ }^{2}$
}

\begin{abstract}
Hydroxyl-terminated liquid natural rubber (HTNR) was prepared by the photo-Fenton reaction, which was carried out in solution in the presence of $\mathrm{H}_{2} \mathrm{O}_{2} / \mathrm{Fe}$ (II) combined with UV irradiation. The HTNR obtained was characterized by GPC, FT-IR, ${ }^{1} \mathrm{H}-\mathrm{NMR},{ }^{13} \mathrm{C}-\mathrm{NMR}$, DEPT-NMR spectroscopy as well as by chemical methods. A probable mechanism leading to the formation of HTNR was discussed based on the analytical data.
\end{abstract}

Key words: Synthesis; natural rubber; liquid natural rubber; FT-IR; gel permeation chromatography (GPC); epoxy; UV irradiation

Basically, the methods for the preparation of liquid natural rubbers (LNRs) involve controlled degradation or depolymerization of the natural rubber (NR) backbone via oxidative chain scissions by either chemical or photochemical routes. Thus far, several methods leading to the production of LNRs have been developed and can be placed into three main categories, i.e. redox, photochemical degradation and oxidation at high temperature and pressure. Of these methods, the redox and photochemical methods have received the most attention (Ravindran et al. 1988).

According to the first method, NR in the latex stage or in an organic solvent was degraded on a large scale by the redox reagent phenylhydrazine and atmospheric oxygen at $50^{\circ}-70^{\circ} \mathrm{C}$. The method yielded LNRs with terminal carbonyl groups which in the presence of excess phenylhydrazine were transformed into phenylhydrazones (Nor \& Ebdon 1988). Concerning the photochemical method, Gupta et al. obtained hydroxyl-terminated liquid natural rubbers (HTNRs) using hydrogen peroxide as the reagent at high temperature and pressure, while Ravindran and coworkers reported the production of HTNRs by photochemical depolymerization of NR toluene solution at room temperature in the presence of $\mathrm{H}_{2} \mathrm{O}_{2}$ and homogenizing agents such as methanol and THF (Ravindran et al. 1988; Nor \& Ebdon 1988).

It is well known that the catalyzation of hydrogen peroxide by ferrous sulfate, Fenton's reagent, is one of the most common advanced oxidation processes. Fenton's reaction is defined as the catalytic generation of hydroxyl radical resulting from the chain reaction between ferrous ion and hydrogen peroxide, and organic compounds could be oxidized according the chain reaction mechanism (Kang \& Kwang 2000; Zhang et al. 2005). Recent reports indicate that a combination of $\mathrm{H}_{2} \mathrm{O}_{2} / \mathrm{UV}$ irradiation with $\mathrm{Fe}$ (II), the so-called the photo-Fenton process, can significantly enhance decomposition of a variety of organic compounds, including

\footnotetext{
${ }^{1}$ Institute of Chemistry, Vietnam Academy of Science and Technology, 18-Hoang Quoc Viet Road, Cau Giay District, Hanoi, Vietnam.

${ }^{2}$ University of Vinh, Nghean, Vietnam.

* Corresponding author (e-mail: huulyp@yahoo.com.vn)
} 
depolymerization of a variety of polymers, such as the different copolymers of acrylamide and acrylic acid (Mai et al. 2002), polychloroprene (Freitas et al. 2005), aminosilicone polymer (Teixeira et al. 2005), NR and polychloroprene/ NR blends (Freitas et al. 2008), and PVA (Lei et al. 1998; Giroto et al. 2006).

In this paper, we report some results that concern the preparation of HTNR by the photo-Fenton reaction, the characterization of the HTNR obtained by GPC, FTIR, ${ }^{1} \mathrm{H}-\mathrm{NMR}$, ${ }^{13} \mathrm{C}$-NMR spectroscopy as well as by chemical methods. The mechanism of depolymerization and hydroxylation of NR to form HTNR based on the analytical data is also discussed in this study.

\section{EXPERIMENTAL}

\section{Materials}

Natural crumb rubber (SVR20, Mn 780,000) was supplied by the Dong Duong Group, Vietnam. Toluene, methanol, and tetrahydrofuran (THF) were of reagent grade and used as received. Hydroquinone ReagentPlus ${ }^{\circledR}$ from Aldrich was used. Santowhite MK, the non-staining antioxidant and phenyl- $\beta$-naphthylamine were obtained from Merck. FeSO $4.7 \mathrm{H}_{2} \mathrm{O}, \mathrm{H}_{2} \mathrm{O}_{2}(30 \%$, w/w), $\mathrm{H}_{2} \mathrm{SO}_{4}$, were also purchased from Merck. All other chemicals and solvents were of purest grade commercially available and used without further purification.

\section{Experimental Procedure}

Natural crumb rubber was masticated for 30 min at $40^{\circ} \mathrm{C} .10 \mathrm{~g}$ of it was dissolved in 100 $\mathrm{ml}$ of toluene and the solution was charged in a reactor, a flat-bottomed borosilicate glass flask of $250 \mathrm{ml}$ capacity fitted with a water condenser, a magnetic stirrer and a water bath. Precise amounts of Fenton reagent (Fe (II) and $\mathrm{H}_{2} \mathrm{O}_{2}$ ) were added dropwise and continuously stirred with a magnetic bar. The mixture was homogenized to a certain extent by the addition of $25 \mathrm{ml}$ of THF.
The $\mathrm{pH}$ of the solution was adjusted with $\mathrm{H}_{2} \mathrm{SO}_{4}$ and /or $\mathrm{NaOH}$ solution in THF. All experiments were conducted at $\mathrm{pH} \sim 2.5-3.0$, and the $\mathrm{H}_{2} \mathrm{O}_{2} / \mathrm{Fe}$ (II) molar ratio was maintained at 1.5 because these values were optimum for the photo-Fenton reaction (Piglatello et al. 1999; Giang 2010). The reaction temperature was varied from $30^{\circ} \mathrm{C}$ to $70^{\circ} \mathrm{C}$ using a water bath for a reaction time period of $1 \mathrm{~h}$ to $50 \mathrm{~h}$.

For the experiment, a $160 \mathrm{~W}$ high pressure Hg lamp was used as a UV light source. The beam was parallel and the length between the lamp and the reactor wall was $3 \mathrm{~cm}$.

After about $32 \mathrm{~h}$ of irradiation, $0.2 \mathrm{~g}$ hydroquinone (about $0.02 \% \mathrm{w} / \mathrm{v}$ of the reaction mixture) was dispersed in the solution and that was allowed to stand for a certain time. A layer of water separated at the bottom along with some white deposits as by-products. These were removed, and liquefied rubber was recovered from the top toluene layer by distilling off the solvent under low pressure. The product was finally washed successively with water and methanol, treated with $0.6 \% \mathrm{w} / \mathrm{w}$ Santowhite MK antioxidant and finally vacuum dried. The sample for analysis was purified further by repeated precipitation of methanol from the toluene solution and dried in a vacuum oven. The by-product was finally washed with methanol and dried in a vacuum to obtain a $7 \%-8 \%$ yield of highly viscid material.

\section{Measurements}

The molecular weights and molecular weight distribution of the original NR as well as those of the HTNRs were determined by a gel permeation chromatography (GPC) system equipped with a series of PL aquagel-OH columns (one Guard $8 \mu \mathrm{m}, 50 \times 7.5 \mathrm{~mm}$ and two MIXED $8 \mu \mathrm{m}, 300 \times 7.5 \mathrm{~mm}$, PLL Laboratories, UK), and a refractive index (RI) detector (RI2000-F, SFD, Torrance, CA), using polystyrene standards of different molecular weight and narrow polydispersity to produce a 
calibration curve. The mobile phase was $1.0 \mathrm{ml} /$ min, and the columns and the RI detector cell were maintained at $30^{\circ} \mathrm{C}$. The molecular weight $(\mathrm{Mn})$ of the original NR, as determined by the above-mentioned methods, was about 780000 . A sample of HTNR having Mn 3060 was used throughout this study for characterization by ${ }^{1} \mathrm{H}-\mathrm{NMR},{ }^{13} \mathrm{C}-\mathrm{NMR}$, DEPT-NMR and FTIR analyses. This sample of HTNR would also be used to modify bisphenol-A diglycidyl eterbased epoxy (DGEBA), the results of which were going to be published in the other article in this issue of ASEAN J. Sc. Technol. Dev., pp. 22-28.

The ${ }^{1} \mathrm{H}-\mathrm{NMR},{ }^{13} \mathrm{C}-\mathrm{NMR}$ and DEPT-NMR spectra of the investigated samples were recorded from a solution in $\mathrm{CDCl}_{3}$ using NMR spectrometer (NMR-Brucker-500 MHz). FTIR analysis was performed on a FTIR IMPACT 410 spectrometer and the samples were scanned from $400-4000 \mathrm{~cm}^{-1}$.

Hydroxyl, hydroperoxide, carboxyl, and carbonyl groups were estimated using standard methods (Krause et al. 1983).

\section{RESULTS AND DISCUSSION}

\section{Characterization of Hydroxyl-terminated Liquid Natural Rubber (HTNR)}

The original natural rubber (NR) and the product obtained by the photo-Fenton process, HTNR, were analyzed by FTIR, ${ }^{1} \mathrm{H}-\mathrm{NMR}$, ${ }^{13} \mathrm{C}$-NRM, DEPT- NMR, and other chemical methods.

The following absorptions were observed in the IR spectra, both of the original NR (Figure 1a) and of HTNR (Figure 1b): $3032 \mathrm{~cm}^{-1}(\mathrm{~m})$, $2958 \mathrm{~cm}^{-1}$ (s), $2862 \mathrm{~cm}^{-1}$ (s), $2726 \mathrm{~cm}^{-1}$ (s) (C-H str.); $1661 \mathrm{~cm}^{-1}$ (m, C=C, cis-vinylene); $1446 \mathrm{~cm}^{-1}$ (s), $1377 \mathrm{~cm}^{-1}$ (s) (C-H def.); $891 \mathrm{~cm}^{-1}$ (m, $-\mathrm{CH}_{3}$ def.); $842 \mathrm{~cm}^{-1}$ (s, C-H out of plane def. in $-\mathrm{CHR}=\mathrm{CCR}^{1}$ ).

Apart from the major IR absorption band characteristics for cis-1,4-polyisoprene (cis-1,4-PIP), other IR absorptions were also observed in the FTIR spectrum of HTNR (Figure $1 b$ ): a broad absorption band at 3600$3400 \mathrm{~cm}^{-1}$, characteristic of $\mathrm{OH}$ stretching vibration; an absorption band at $1310 \mathrm{~cm}^{-1}$

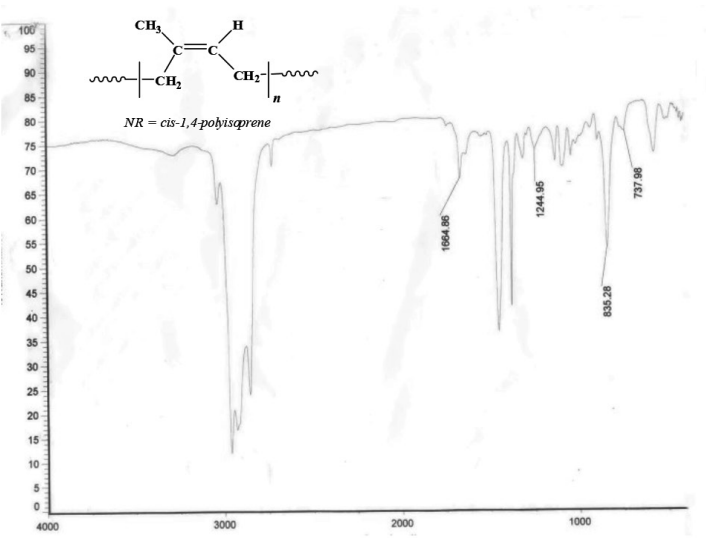

(a)

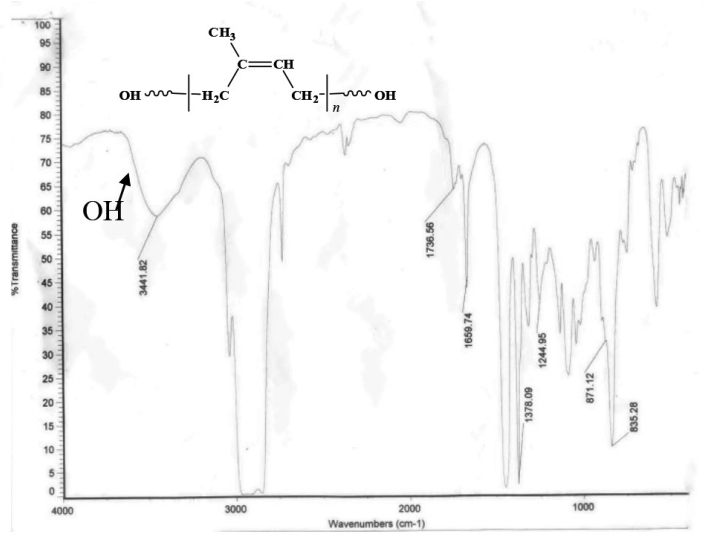

(b)

Figure 1. FTIR spectrum of (a) NR and (b) HTNR prepared by the photo-Fenton process. 
(m, C-O str., aliph.primary.alcohol) that confirmed the presence of primary hydroxyl groups in the depolymerized product, i.e. in the HTNR.

The ${ }^{1} \mathrm{H}-\mathrm{NMR}$ and ${ }^{13} \mathrm{C}-\mathrm{NMR}$ spectra in $\mathrm{CDCl}_{3}$ at $28^{\circ} \mathrm{C}$ of the depolymerized product (Figures $2 a, b$ and $3 a, b$ ) lent further support to the above conclusion. ${ }^{1} \mathrm{H}-\mathrm{NMR}: \delta=1.679$ p.p.m. $\left[\mathrm{s} ;-\mathrm{CH}_{3}(5), 3 \mathrm{H}\right] ; \delta=2.042$ p.p.m. [brs; $-\mathrm{CH}_{2}-(1)$ and $\left.-\mathrm{CH}_{2}-(4), 4 \mathrm{H}\right] ; \delta=5.125$ p.p.m. [m; $\mathrm{CH}(3)$, $1 \mathrm{H}]$. The spectrum also contained minor peaks at $\delta$ from 1.254 ppm to 1.611 p.p.m., indicating the probable presence of side products. A minor peak was observed at around $\delta \sim 2.69$ ppm (Figure $2 b$ ) in the ${ }^{1} \mathrm{H}-\mathrm{NMR}$ of HTNR prepared by the photo-Fenton reaction due to the formation of an epoxy group, i.e. the proton attached to the oxirane ring (Burfield et al. 1984), whereas it was not observed in the ${ }^{1} \mathrm{H}-\mathrm{NMR}$ of the original NR (Figure $2 a$ ).

The signal due to the hydroxyl proton in the hydroxymethyl group is usually observed around $\delta=4.0$ p.p.m. to 4.2 p.p.m. This however, could not be detected in the present case, since the signal / noise ratio was too unfavorable to see the end groups.

The ${ }^{13} \mathrm{C}$-NMR spectrum indicated ${ }^{13} \mathrm{C}$ shieldings, typical of cis-1,4-PIP at the following positions: $\mathrm{C}^{1}: \delta=32.23$ p.p.m.; $\mathrm{C}^{2}: \delta=135.16$ p.p.m.; $\mathrm{C}^{3}: \delta=125.03$ p.p.m.; $\mathrm{C}^{4}: \delta=26.38$ p.p.m.; $\mathrm{C}^{5}: \delta=23.4$ p.p.m. (Equation 10).

Apart from these major peaks the spectrum also contained minor peaks at $\delta=78.39,76.98$ and 75.57 p.p.m. due to $\mathrm{CDCl}_{3}$. Other minor peaks at $\delta=60.847$ and 64.540 p.p.m. could be due to $\alpha$-carbons attached to the hydroxyl groups in structures like (I) and (II), respectively and hence could indeed correspond to an $\alpha$-hydroxymethyl group. The allylic hydroxyl protons in the ${ }^{1} \mathrm{H}-\mathrm{NMR}$ spectra were masked by the multiples at $\delta=5.125$ p.p.m. of the $>C=C-H$ protons (Equation 9). Several minor peaks could also be observed at $\delta$ from 2.00 to 3.53 p.p.m. in the ${ }^{13} \mathrm{C}$-NMR spectrum of HTNR (Figure $3 b$ ), indicating the probable side products due to the formation of epoxy group.

The broad $\mathrm{OH}$ stretching band at $3600 \mathrm{~cm}^{-1}$ $-3400 \mathrm{~cm}^{-1}$ in the FTIR spectrum of the HTNR (Figure $1 b$ ) and also the peaks at $\delta=60.847$ p.p.m. and 64.540 p.p.m. (Figure $3 b$ ) which were characteristic of the $\alpha$-carbons of allylalcohol in the ${ }^{13} \mathrm{C}-\mathrm{NMR}$ spectrum of HTNR suggest the terminal hydroxyl groups in the product. The allylic hydroxyl protons in the ${ }^{1} \mathrm{H}-\mathrm{NMR}$ spectra were masked by the multiples at $\delta=5.125$ p.p.m. of the $>\mathrm{C}=\mathrm{C}-\mathrm{H}$ protons.

All the other signal characteristics for both NR and HTNR were observed in the ${ }^{1} \mathrm{H}-\mathrm{NMR}$

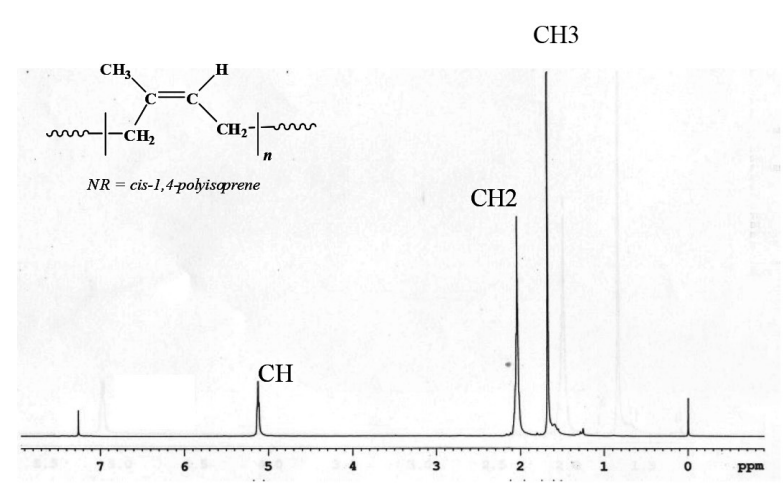

(a)

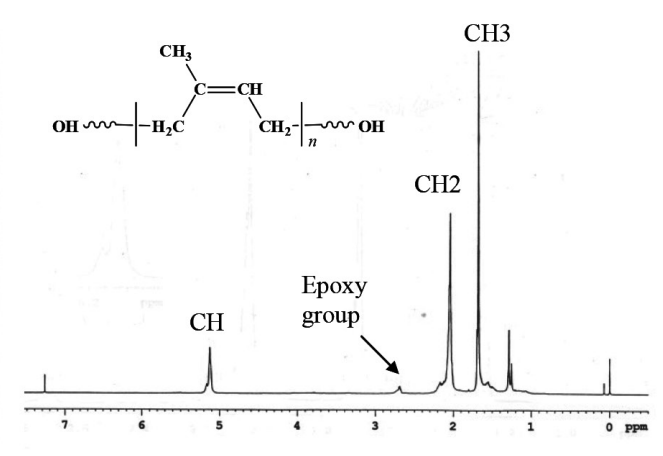

(b)

Figure 2. ${ }^{1} H$-NMR spectrum of NR(a) and HTNR(b) prepared by the photo-Fenton reaction. 


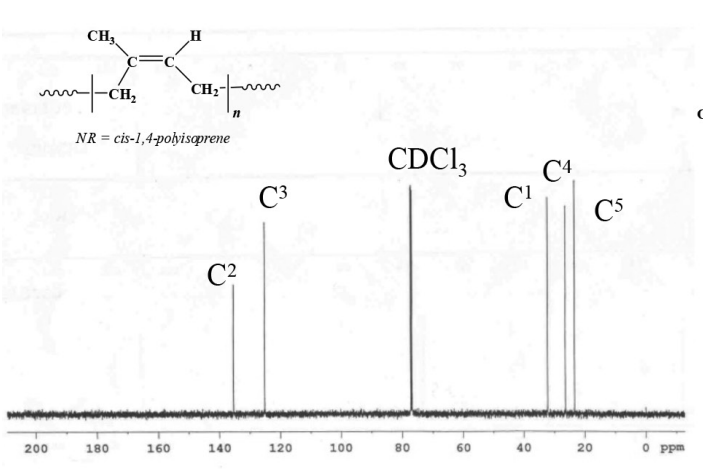

(a)

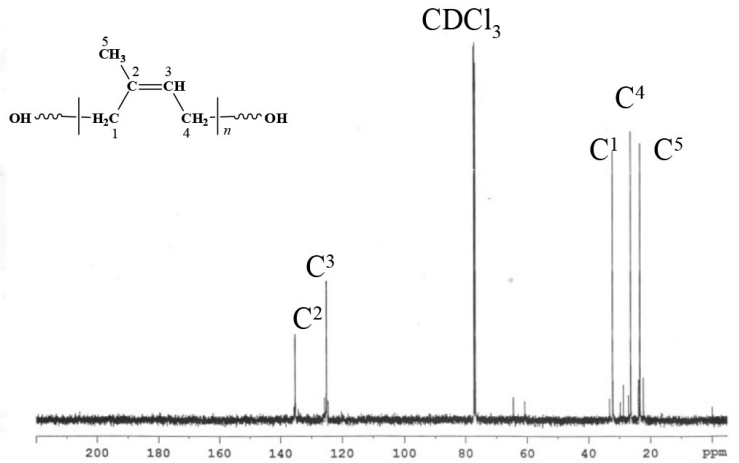

(b)

Figure 3. ${ }^{13} \mathrm{C}-\mathrm{NMR}$ spectrum of NR (a), and HTNR (b), prepared by the photo-Fenton process.

spectrum (Figures $2 a, b): \delta=5.08$ p.p.m., $(=\mathrm{CH}) ; \delta=2.00$ p.p.m., $\left(-\mathrm{CH}_{2}-\right) ; \delta=1.67$ p.p.m., $\left(-\mathrm{CH}_{3}\right)$, as well as in the ${ }^{13} \mathrm{C}-\mathrm{NMR}$ spectrum (Figure 3$)$ : $\delta=135.012$ p.p.m., $\left(\mathrm{C}_{2}\right.$ atom); $\delta=124.900$ p.p.m., $\left(\mathrm{C}_{3}\right.$ atom); $\delta=32.216$ p.p.m., $\left(\mathrm{C}_{1}\right.$ atom); $\delta=26.409$ p.p.m., $\left(\mathrm{C}_{4}\right.$ atom $)$; and $\delta=23.433$ p.p.m., $\left(\mathrm{C}_{5}\right.$ atom). The cis-1,4-PIP configuration of both NR and LNRs were preserved in the DEPT-NMR spectrum (Figure 4). The main absorption bands, characteristic of NR, were also preserved in the FTIR spectra. All these indicated that the cis-1,4-PIP configuration was not disturbed during the depolymerization process. Further evidence was the fact that there was no observed change in the absorption band of the isoprene unit, i.e. at $836 \mathrm{~cm}^{-1}$ in the FTIR spectrum (Figures 1a, b).

The hydroxyl value estimated for HTNR was $27.12 \mathrm{mg}$ of $\mathrm{KOH} / \mathrm{g}$, which gave it a hydroxyl functionality of $1.97-1.98$. The product readily reacts with diisocyanates such as toluene diisocyanate, leading to chain extention.

\section{Mechanism of Depolymerization of NR by the Photo-Fenton Process}

It is well known that in the photo-Fenton process, the reaction between $\mathrm{H}_{2} \mathrm{O}_{2}$ and ferrous salt, i.e. the Fenton reaction, the primary reactions in representative Fenton process are (Yang et al. 2005).

$$
\begin{aligned}
& \mathrm{Fe}^{2+}+\mathrm{H}_{2} \mathrm{O}_{2}+\mathrm{H}^{+} \rightarrow \mathrm{Fe}^{3+}+\mathrm{HO} \bullet+\mathrm{H}_{2} \mathrm{O}\left(\mathrm{k}_{1}=58 \mathrm{~mol}^{-1} \mathrm{dm}^{3} \cdot \mathrm{s}^{-1}\right) \\
& \mathrm{Fe}^{3+}+\mathrm{H}_{2} \mathrm{O}_{2} \rightarrow \mathrm{Fe}^{2+}+\mathrm{H}^{+}+\mathrm{HOO}^{\bullet}\left(\mathrm{k}_{2}=0.02 \mathrm{~mol}^{-1} \mathrm{dm}^{3} \cdot \mathrm{s}^{-1}\right)
\end{aligned}
$$

As seen from Equations 1 and 2, the decomposition of $\mathrm{H}_{2} \mathrm{O}_{2}$ by iron ions is through the interaction between $\mathrm{Fe}^{2+}$ and $\mathrm{Fe}^{3+}$. As the reaction rate in Equation 1 was faster than that of Equation 2, $\mathrm{Fe}^{2+}$ was rapidly oxidized to $\mathrm{Fe}^{3+}$ in the reaction process. Therefore, the concentration of ${ }^{\bullet} \mathrm{OH}$ in the solution rapidly increased and could degrade the NR macromolecule. In addition, from Equation 2 it could be seen that $\mathrm{Fe}^{2+}$ could be re-generated from the reduction of $\mathrm{Fe}^{3+}$, leading to the continuous generation of $\bullet \mathrm{OH}$. The combination of thermal process and UV irradiation enabled the oxidation power of Fenton reagent to be significantly increased due mainly to the photo-reduction of $\mathrm{Fe}(\mathrm{III})$ to $\mathrm{Fe}(\mathrm{II})$, which could react with $\mathrm{H}_{2} \mathrm{O}_{2}$ establishing a cycle mechanism of generating additional ${ }^{\circ} \mathrm{OH}$ by Equation 3.

$$
\mathrm{Fe}^{3+}+\mathrm{H}_{2} \mathrm{O}_{2}+\mathrm{h} v \rightarrow \mathrm{Fe}^{2+}+\mathrm{OH}^{\bullet}+\mathrm{H}^{+}
$$




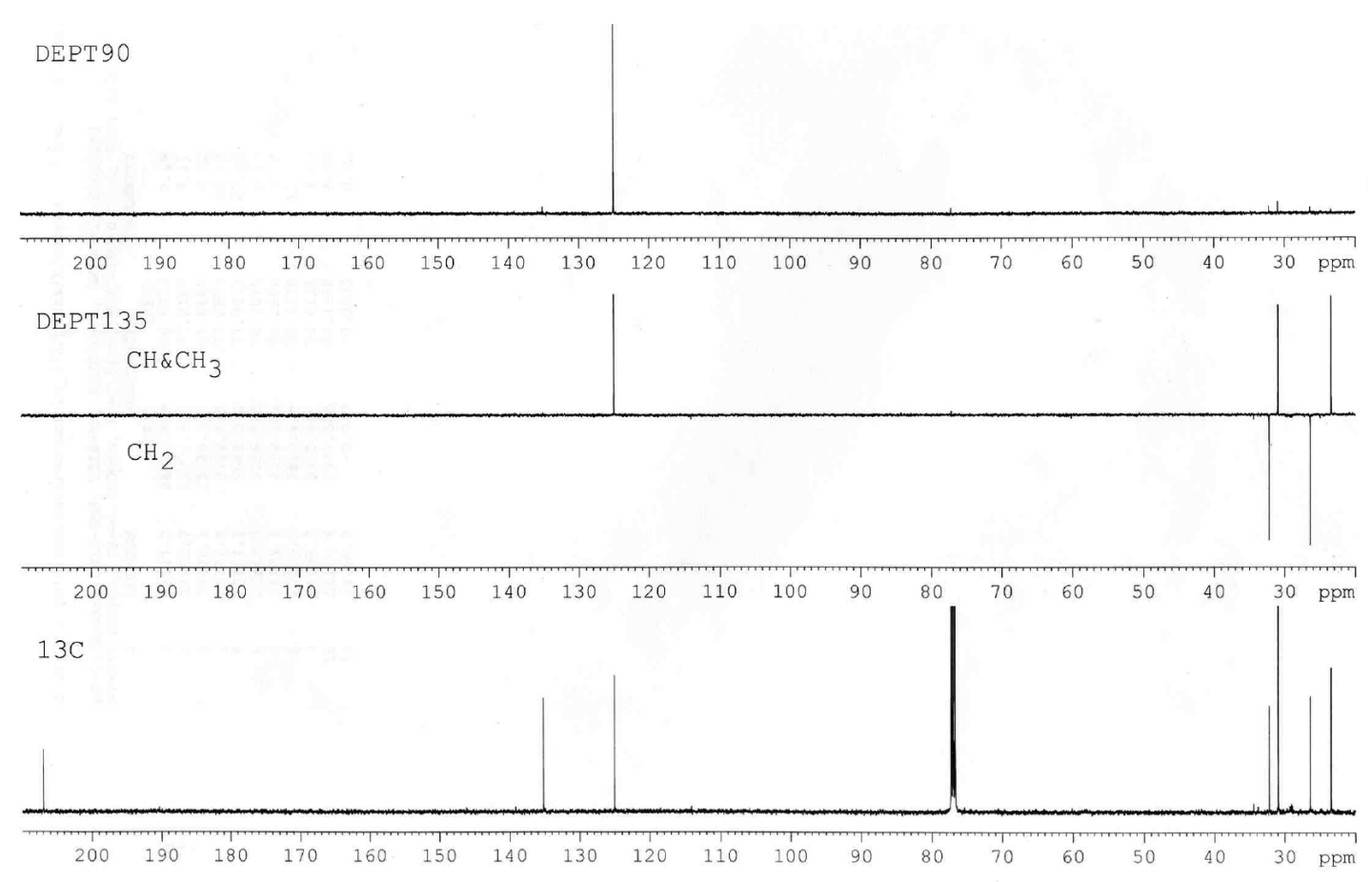

Figure 4. DEPT spectra of HTNR prepared by the photo-Fenton reaction.

The hydrogen peroxide used in the degradation process is susceptible to decomposition under the influence of radiation. Although hydrogen peroxide has an absorption maximum at $254 \mathrm{~nm}$; it interacts with radiation up to $370 \mathrm{~nm}$, yielding hydroxyl radicals. If hydrogen peroxide and hydroxyl radicals were in excess, competitive reactions could take place (Yang et al. 2005). Hydroxyl radicals are prone to recombination or to reactions according to the following schemes:

$$
\begin{array}{ll}
\mathrm{OH}^{\bullet}+\mathrm{H}_{2} \mathrm{O}_{2} \rightarrow \mathrm{HOO}^{\bullet}+\mathrm{H}_{2} \mathrm{O} & \left(\mathrm{k}_{3}=2.7 \times 10^{7} \mathrm{~mol}^{-1} \mathrm{dm}^{3} \cdot \mathrm{s}^{-1}\right) \\
\mathrm{HOO}^{\bullet}+\mathrm{H}_{2} \mathrm{O}_{2} \rightarrow \mathrm{OH}^{\bullet}+\mathrm{H}_{2} \mathrm{O}+\mathrm{O}_{2} & \left(\mathrm{k}_{4}=0.5 \pm 0.009 \mathrm{~mol}^{-1} \mathrm{dm}^{3} \cdot \mathrm{s}^{-1}\right) \\
2 \mathrm{HOO}^{\bullet} \rightarrow \mathrm{O}_{2}+\mathrm{H}_{2} \mathrm{O}_{2} & \left(\mathrm{k}_{5}=8.3 \times 10^{5} \mathrm{~mol}^{-1} \mathrm{dm}^{3} \cdot \mathrm{s}^{-1}\right) \\
2 \mathrm{HOO}^{\bullet}+\mathrm{OH}^{\bullet} \rightarrow \mathrm{O}_{2}+\mathrm{H}_{2} \mathrm{O}_{2} & \left(\mathrm{k}_{6}=1.0 \times 10^{10} \mathrm{~mol}^{-1} \mathrm{dm}^{3} \cdot \mathrm{s}^{-1}\right) \\
2 \mathrm{OH}^{\bullet} \rightarrow \mathrm{H}_{2} \mathrm{O}_{2} & \left(\mathrm{k}_{7}=4.2 \times 10^{9} \mathrm{~mol}^{-1} \mathrm{dm}^{3} \cdot \mathrm{s}^{-1}\right)
\end{array}
$$

Ravindran and co-workers (1988) have demonstrated the existence of Structures 1 and 2 in the depolymerized products: 
<smiles>CC(C)=CCO</smiles>

(I)

$\underline{\text { Structure } 1}$<smiles>CC=C(C)CO</smiles>

(II)

$\underline{\text { Structure } 2}$

The generation of such structural entities entails the cleavage of the original rubber molecule between the $\alpha$-carbon atoms. In the case of NR, the $\sigma$ bond between $\alpha$ - methylenic groups which connect the isoprene units are not in the same plane with the double bonds. This is because there is a tendency of coiling up of the rubber segments due to its cis configuration (Structure 3):

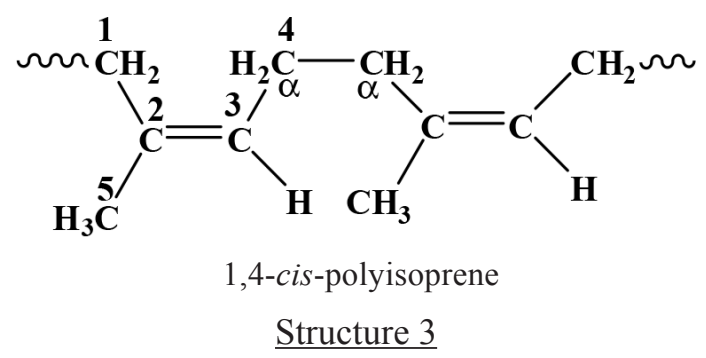

The steric hindrance caused by such an unbalanced structure with pendent methyl groups weakens the $-\mathrm{CH}_{2}-\mathrm{CH}_{2}$ - bond, leading to its rupture under certain conditions which could be provided by thermal energy or chain modifications caused by radical species or by radiation.

Based on the above analytical data, the mechanism for the depolymerization of NR by the photo-Fenton process leading to the formation of HTNR could be suggested to be as below (Structure 4).

$$
\mathrm{H}_{2} \mathrm{O}_{2} \stackrel{h v}{\longrightarrow} \mathbf{H}_{2} \mathrm{O}_{2}^{*} \longrightarrow 2 \dot{\mathrm{OH}}
$$

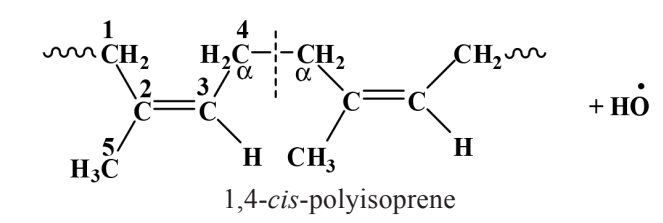<smiles>C/C=C(\C=C\CO)CO</smiles>

$\underline{\text { Structure } 4}$

\section{CONCLUSIONS}

Hydroxyl-terminated liquid natural rubber (HTNR) was successfully prepared by the Photo-Fenton reaction, which was carried out in solution in the presence of $\mathrm{H}_{2} \mathrm{O}_{2} / \mathrm{Fe}$ (II) combined with UV irradiation. The HTNRs obtained were characterized by FTIR, ${ }^{1} \mathrm{H}-\mathrm{NMR}$, ${ }^{13} \mathrm{C}$-NMR and DEPT-NMR spectroscopy as well as by chemical methods. A probable mechanism leading to the formation of HTNR was discussed based on the analytical data.

\section{ACKNOWLEDGEMENT}

This study was supported by the Vietnam's National Foundation for Science and Technology Development (NAFOSTED, 104.04.70.09).

Date of submission: January 2014

Date of acceptance: March 2014 


\section{REFERENCES}

Burfield, DR, Lim, KL, Law, KS \& Soon, Ng 1984, 'Analysis of epoxidized natural rubber. A comparative study of D.S.C., N.M.R., elemental analysis and direct titration methods', Polymer, vol. 25, pp. 995-998.

Freitas, AR, Vidotti, GJ, Rubira, AF \& Muniz, EC 2005, 'Polychloroprene degradation by a PhotoFenton process', Polym. Deg. Stab., vol. 87, pp. 425-432.

Freitas, AR, Vidotti, GJ, Rubira, AF \& Muniz, EC 2008, 'Degradation of polychloroprene/natural rubber $(\mathrm{PCP} / \mathrm{NR})$ blends by photo-Fenton process', Polym. Deg. Stab., vol. 93, pp. 601-607.

Giang, LD 2010, 'Modification of epoxy resin with epoxidized liquid natural rubber' (in Vietnamese), PhD Thesis, Univesity of Vinh.

Giroto, JA, Guardani, R, Teixeira ACSC \& Nascimento, CAO 2006, 'Study on the photoFenton degradation of polyvinyl alcohol in aqueous solution', Chem. Eng. Proc., vol. 45, pp. 523-532.

Kang, YW \& Kwang, KY 2000, 'Effect of reaction conditions on the oxidation efficiency in the Fenton process', Water Res., vol. 34, pp. 27862790.

Krause, A, Lange, A \& Erzin, M 1983, Plastic analysis guide, Macmillan, New York.

Lei, L, Hu X, Yue, PL, Bossmann, SH, Glib, S \& Braun, AM 1998, 'Oxidative degradation of polyvinyl alcohol by the photochemically enhanced Fenton reaction', J. Photochem Photobiol, A : Chemistry, vol. 116, pp. 159-166.
Mai, C, Majcherczyk, A, Schormann, W \& Huttermann, A 2002, 'Degradation of acrylic copolymers by Fenton's reagent', Polym. Deg. Stab., vol. 75, pp. 107-112.

Neyens, E \& Baeyens, J 2003, 'A review of clasical Fenton's peroxidation as an advance oxidation technique', J. Hazard Mater., vol. B98, pp. $33-50$.

Nor, HM \& Ebdon, JR 1998, 'Telechelic liquid natural rubber: a review', Prog. Polym. Sci., vol. 23, no.1, pp. 143-177.

Piglatello, JJ, Liu, D \& Huston, P 1999, 'Evidence for an additional oxidant in the photo-assisted Fenton reaction', Environ. Sci. Technol., vol. 33, pp. 1832-1839.

Ravindran, T, Gopinathan, NMR \& Francis, JD 1988, 'Production of hydroxyl-terminated liquid natural rubber-mechanism of photochemical depolymerization and hydroxylation', J. Appl. Polym. Sci., vol. 35, no. 5, pp. 1227-1239.

Teixeira, ACSC, Guardani, RG, Braun, AM, Oliveros, E \& Nascimento CAO 2005, 'Degradation of an aminosilicone polymer in a water emulsion by the Fenton and the photochemically enhanced Fenton reactions, Chem. Eng. Proc., vol. 44, pp. 923-931.

Zhang, H, Choi, HZ \& Huang, CP 2005, 'Optimization of Fenton process for the treatment of landfill leachate', J. Hazard Mater., vol. B125, pp. 166-174.

Yang, GP, Zhao, XK, Sun, XJ \& Lu, XL 2005, 'Oxidative degradation of diethyl phthalate by photochemically-enhanced Fenton reaction', J. Hazard Mater, vol. B126, pp. 112-118. 